\title{
Small-dose intrathecal morphine and perioperative alpha-2 agonists with lidocaïne infusions in a patient with Rett Syndrome undergoing scoliosis surgery. A case report
}

\author{
O. Stiennon ${ }^{1}$, L. Van Der Essen¹, G. Samouri1, R. Rossillon², N. Parisi¹. \\ 1Saint Pierre, Anesthesiology, Ottignies, Belgium. \\ 2Saint Pierre, Orthopedics Surgery, Ottignies, Belgium.
}

Rett syndrome is a a rare genetic neurological disorder due to a mutation of MECP gene on chromosome X. Mains features that concerns anaesthesiologists are the obstructive sleep apnea, epilepsy, autonomic disturbance, long QT interval and high sensitivity to opioids and sedative agents.

We report the case of a girl aged $14(1 \mathrm{~m} 51,50 \mathrm{~kg})$, affected by Rett syndrome, complicated by a scoliosis (neuromuscular type) progressing quickly in spite of wearing a corset since 2013. Our case reports the analgesia results observed with our optimised management without complication or respiratory event. The surgery consisted in a posterior spinal instrumentation and fusion.

After inhalatory induction (sevoflurane and nitrogen oxide), anesthesia was maintained with propofol with TIVA Schnider's model, lidocaïne $2 \mathrm{mg} / \mathrm{kg} / \mathrm{h}$, ketamine $0.25 \mathrm{mg} / \mathrm{kg} / \mathrm{h}$ and dexmedetomidine $1 \mu \mathrm{g} / \mathrm{kg} / \mathrm{h}$ during paravertebral muscles dissection, then $0.7 \mu \mathrm{g} / \mathrm{kg} / \mathrm{h}$ during the fusion, and stopped when reduction is complete. The surgeon realised himself a spinal injection of morphine $(1 \mathrm{mcg} / \mathrm{kg})$. The patient stayed hemodynamically stable during the 5 hours of surgery (figure 2). She was extubated in the operating room with a non complicated weaning from mechanical ventilation.

The patient was transferred extubated to intensive care with $\mathrm{FiO} 250 \%$ and a noradrenalin infusion to treat transient vasoplegia, it was stopped on day 1 .

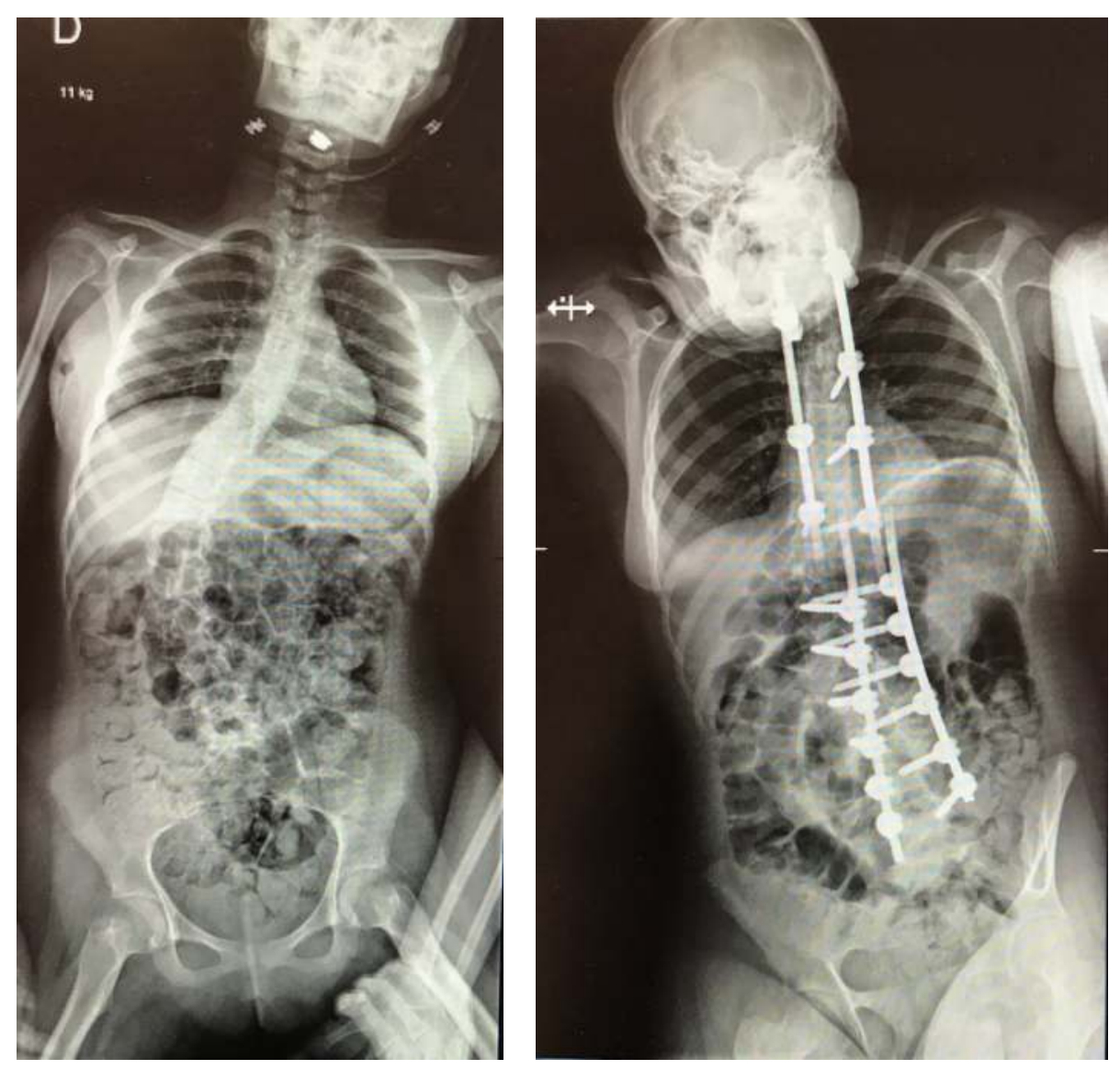

Figure 1: Lumbar spine radio before (Cobb angle $53^{\circ}$ between T8 and L4) and after surgery
On day 0 , a moderate prolonged sedation was observed, with a positive Naloxone test due to spinal analgesia but she had neither respiratory nor haemodynamic complication.

The postoperative pain management consisted in paracetamol $(60 \mathrm{mg} / \mathrm{kg} / \mathrm{d})$, ketorolac $(0,5 \mathrm{mg} / \mathrm{kg} /$ $8 \mathrm{hrs})$ and lidocaïne infusion $(1,33 \mathrm{mg} / \mathrm{kg} / \mathrm{h}$ for 48 hours). As no verbal communication was possible, pain was evaluated with the FLACC scale (figure $3)$.

No non-invasive ventilation was necessary, nasal prongs delivered oxygen until day 2 . After 2 days in intensive care, the patient returned to the pediatric unit. No PCA with opioid was needed, with very good control of analgesia and comfort.

We used smaller dose of intrathecal morphine than advised $(5-10 \mu \mathrm{g} / \mathrm{kg})$ but in this syndrome precaution is advisable with this technique.

Perioperative alpha 2 agonist and lidocaïne seems to be a good alternative to opioids for scoliosis surgery. To our knowledge, no literature is available for the moment on the association of these 3 drugs. Studies on bigger cohorts are needed.

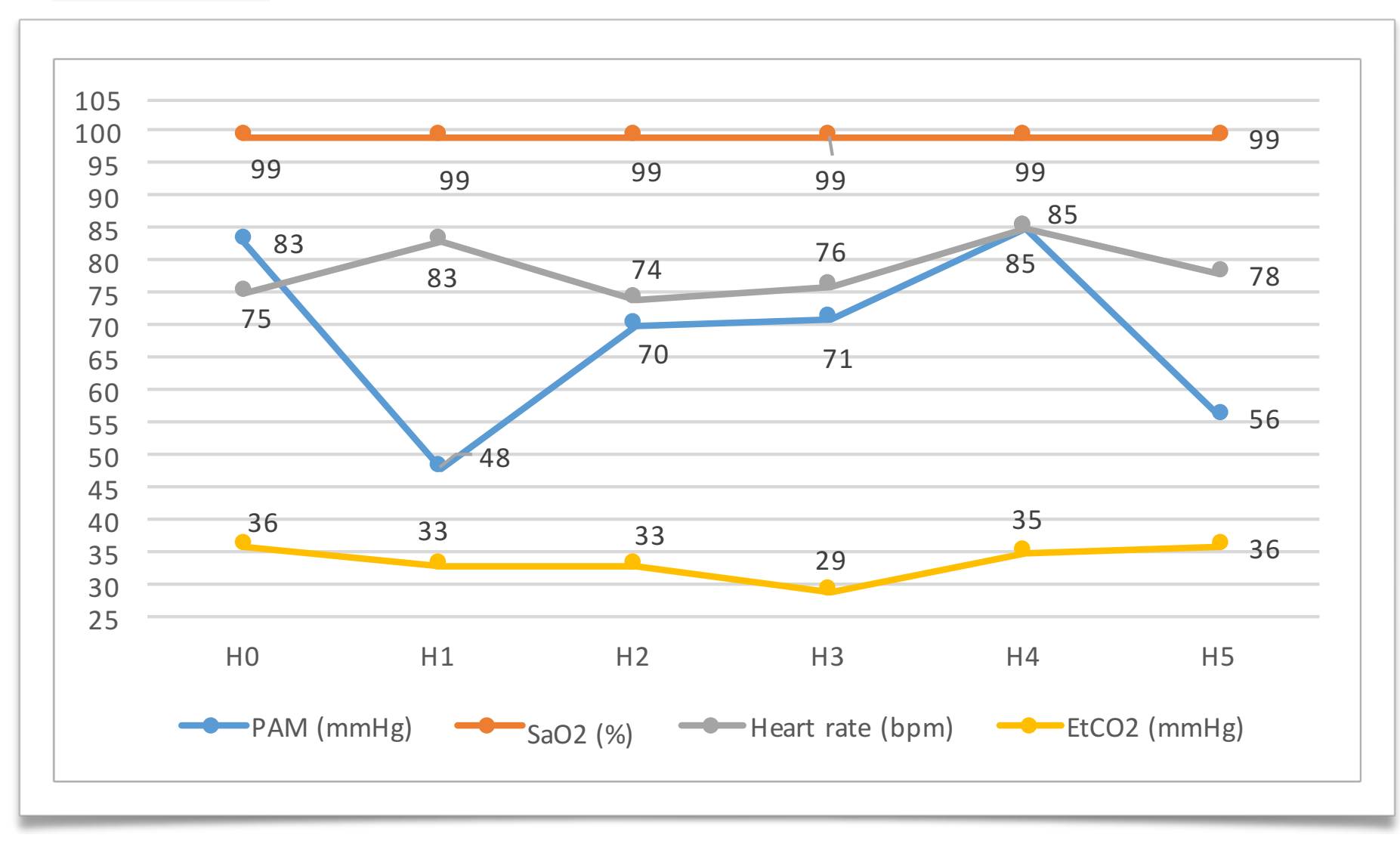

Figure 2: Pain score via FLACC scale with the respiratory parameters of the patient

\begin{tabular}{|l|c|c|c|c|}
\cline { 2 - 5 } \multicolumn{1}{c|}{} & Day 1 & Day 2 & Day 3 & Day 4 \\
\hline FLACC Scale & 1 & 1 & 2 & 1 \\
\hline & & & & \\
SaO2 (\%) & 100 & 97 & 98 & 95 \\
Lpm O2 & 4 & 2 & 0 & 0 \\
Respiratory rate & 13 & 15 & 17 & 18 \\
\hline
\end{tabular}

Figure 3: Intra operative parameters 